\title{
Association of HSCRP with an Increased Risk of Cardiovascular Events in Rattus norvegicus
}

Iddah M. Ali ${ }^{1 *}$, Busolo, Hillary ${ }^{2}$

${ }^{1}$ Department Medical Microbiology and Parasitology, School of Medicine, Masinde Muliro University of Science and Technology, P.O. Box 19050100, Kakamega, Kenya

${ }^{2}$ Department of Marketing, School of Business, Economics and Human Resource Development, Alupe University College, P.O. Box 845-50400, Kakamega, Kenya

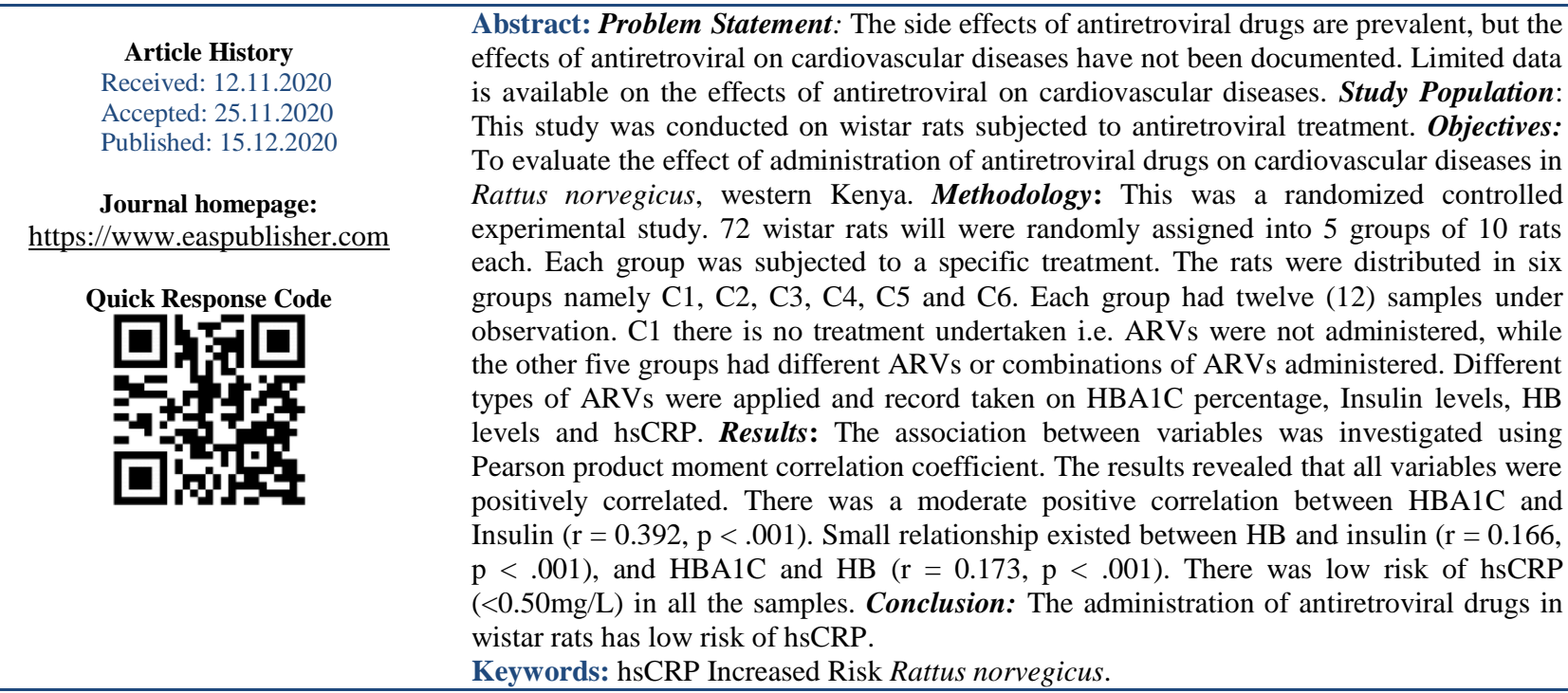

Copyright $\odot 2020$ The Author(s): This is an open-access article distributed under the terms of the Creative Commons Attribution 4.0 International License (CC BY-NC 4.0) which permits unrestricted use, distribution, and reproduction in any medium for non-commercial use provided the original author and source are credited.

\section{INTRODUCTION}

C-reactive protein(CRP) is the most extensively studied of numerous inflammatory biomarkers potentially linked to underlying atherosclerosis in the general population, among whom elevations in CRP are associated with an increased risk of cardiovascular events independent of traditional risk factors.

HIV infection, particularly in men, has been associated with increased CRP levels when compared with uninfected controls [1]. Furthermore, in a study of 922 HIV-infected patients followed for five years, a high CRP was independently associated with increased overall mortality [2]. With regards to the specific morbidity of cardiovascular disease, the association between CRP levels and myocardial infarction (MI) risk in HIV-infected patients was evaluated in a study of a large hospital database that included 487 HIV-infected and 69,870 HIV-uninfected patients [3]. High CRP (any value exceeding the upper limit of normal of the standard assay or any value in the highest quantile of the high sensitivity CRP assay) was found more frequently among HIV-infected patients (59 versus 39 percent). In an adjusted model controlling for age, sex, race, hypertension, diabetes and dyslipidemia, the risk for acute myocardial infarction was increased more than fourfold among patients with HIV infection and elevated CRP when compared with patients with neither risk factor. There was no association between CRP level and HIV viral load or CD4 cell count, but protease inhibitor use was associated with high CRP levels. Hence there is a growing need for simplifying HIV treatment protocols and for having cheaper alternatives for monitoring disease activity.

The effect on antiretroviral therapy (ART) in general on CRP is unclear, with some studies showing an increase [4] and others showing a decrease [5]. Changes in CRP level may depend on the particular agent used [7]. In a study of 244 patients who had been randomly assigned to initiate one of four ART regimens, increases in CRP at weeks 24 and 96 were observed with regimens containing abacavir- 
lamivudine, particularly when used with efavirenz, in contrast to stable levels with tenofovir-emtricitabine or boosted atazanavir [6]. This finding was notable because of an apparent increase in myocardial infarction risk seen with abacavir in a large cohort of HIV-infected patients). However, the study did not analyze the association of such changes in CRP with cardiovascular events, and in fact, the two participants who experienced a myocardial infarction during the study period were receiving tenofovir-emtricitabine and efavirenz. It is unclear whether the association between CRP and cardiovascular events in HIV-infected individuals differs from that among the uninfected population [8].

High-sensitivity C-reactive protein (hsCRP) has been thought to be a potential solution for both these problems. Since hsCRP is considered to be a potential biomarker for predicting long term disease progression and CVD risk, also considered as a marker for predicting mortality and as a tool for routine monitoring of disease activity. hsCRP has the potential to replace traditional costlier measures like CD4 count and HIV RNA load etc. This study measured hsCRP as a potential biomarker for predicting cardiovascular events with other markers such as HBA1C, HB and insulin under in Rattus norvegicus administered with antiretroviral drugs.

\section{Material ANd Methods Study Site and Design}

This study was conducted within the medical physiology and zoology departments of Maseno University in Kisumu County, Kenya. 72 wistar rats, aged 4-5 months weighing $280 \pm 20 \mathrm{~g}$ were randomly selected at the university of Nairobi animal house. This study was a randomized controlled experimental study in which 72 wistar rats were randomly assigned into 5 groups of 12 rats each. Each group was subjected to a specific antiretroviral treatment. The rats were kept for two weeks to acclimatize in their new environment at the Maseno university physiology laboratories. Each animal was weighed and given a serial number ranging from 1 to 10 for each group and labeled appropriately. Their baseline random blood glucose was measured by a glucometer and recorded. Any animal that was to be found to have a random blood glucose levels of more than $16 \mathrm{mM} / \mathrm{L}$ was to be retested again and if confirmed was to be excluded from the procedure and replaced. This parameter was used as a threshold for diagnosing hyperglycemia.

\section{Study Methods}

The study had a population of 72 wistar rats that were distributed in six groups namely $\mathrm{C} 1, \mathrm{C} 2, \mathrm{C} 3$, C4, C5 and C6. Each group had twelve (12) samples under observation. $\mathrm{C} 1$ there was no treatment undertaken i.e. ARVs were not administered, while the other five groups had different ARVs or combinations of ARVs administered. Different types of ARVs were applied and record taken on HBA1C percentage, Insulin levels, HB levels and hsCRP. The wistar rats were the experimental/study animals (animal model). The other main materials for this study included: Lopinavir /Ritonavir [200/50 mg] tablets, Atazanavir/Ritonavir [300/100mg] tablets, Hesperidin/Diosmin [450/50 mg] tablets.

\section{RATS}

72 wistar rats were randomly assigned into five groups of 12 animals and treated as follows. Grou $1 ; .10$ rats -were fed on normal rat diet and used as the control group for the duration of the experiment [28 days].Group 2; 10 rats -were placed on normal diet plus lopinavir/ritonavir at dose of $20 / 5 \mathrm{mg} / \mathrm{kg}$ body weight administered twelve hourly for 28 days.Group 3; 10 rats - were placed on normal diet plus Atazanavir/Ritonavir $30 / 10 \mathrm{mg} / \mathrm{kg}$ body weight administered twelve hourly for 28days.Group 4; 10 rats- were placed on normal diet plus Lopinavir/Ritonavir at a dose of $20 / 5 \mathrm{mg} / \mathrm{kg}$ body weight plus Hesperidin/Diosmin $45 / 5 \mathrm{mg} / \mathrm{kg}$ body weight coadminstered twelve hourly for 28 days.Group $5 ; 10$ rats- were placed on normal diet plus Atazanavir/Ritonavir at a dose of $30 / 10 \mathrm{mg} / \mathrm{kg}$ plus Hesperidin/Diosmin $45 / 5 \mathrm{mg} / \mathrm{kg}$ body weight coadminstered twelve hourly for 28 days.

\section{Ethical Considerations}

This study involved the use of animals. Permission was obtained to use the animals as experimental models from the ethical review board on the use of laboratory animals from the institute of primate research [IPR] / The University of East Africa, Baraton.

\section{STATISTICAl AnAlysis}

Data analysis was done using SPSS version 22.0. Categorical variables were summarized as frequencies (percentage), while the continuous variables were summarized as median (interquartile range).The association between variables were investigated using Pearson product moment correlation coefficient. Normality test was used to asses normality of variables first the original means statistic and 5\% trimmed means statistic of variables in the study were compared.

\section{RESULTS}

The research study investigated the association between ARVs and cardiopathy. There were six groups in this study labelled $\mathrm{C} 1, \mathrm{C} 2, \mathrm{C} 3, \mathrm{C} 4, \mathrm{C} 5$ and C6. C1 there was no treatment undertaken i.e. ARVs were not administered, while the other five groups had different ARVs or combinations of ARVs administered. Each group had 12 samples under observation. Table 1 shows the different ARVs administered. 
Table-1: ARVs administration in groups0-

\begin{tabular}{|l|l|}
\hline Group & ARVs Administered \\
\hline C1 & NO TREATMENT \\
\hline C2 & Lopinanavir/Ritonavir \\
\hline C3 & Atazanavir/ritonavir \\
\hline C4 & Lopinavir/Ritonavir + diosmin/hesperidin \\
\hline C5 & Atazanavir/Ritonavir +diosmin/hesperidin \\
\hline C6 & Diosmin/hesperidin \\
\hline
\end{tabular}

Majority of the samples had HBA1C percentage range between $4.01-6.0 \%$. Normal range of HBA1C was between $4-6 \%$. HBA1C results are presented on table 2 .

Table-2: HBA1C percentage

\begin{tabular}{|l|l|}
\hline Percentage & Number \\
\hline$<4.0$ & 16 \\
\hline $4.01-6.0$ & 52 \\
\hline$>6.01$ & 4 \\
\hline Total & 72 \\
\hline
\end{tabular}

The insulin level for the samples with $<4.0$ HBA1C ranged between $12.1-20.9 \mathrm{mU} / \mathrm{L}$ indication a normal level. HB ranged from $7.5-17.0 \mathrm{~g} / \mathrm{dl}$. Those that were $<11 \mathrm{~g} / \mathrm{dl}$ were three from C5 where Atazanavir/Ritonavir +diosmin/hesperidin ARVs were administered. There was low risk of hsCRP $(<0.50 \mathrm{mg} / \mathrm{L})$ in all the 16 samples.

The 52 samples with $4.0-6.0 \%$ HBA1C had insulin range from $14.2-24.1 \mathrm{~g} / \mathrm{dl}$. Nine of the samples registered insulin range above normal of $22.4-24.1 \mathrm{~g} / \mathrm{dl}$ and came from $\mathrm{C} 2$ and $\mathrm{C} 3$ where Lopinanavir/Ritonavir and Atazanavir/ritonavir ARVs were administered respectively. HB levels ranged between $7.8-17.5 \mathrm{~g} / \mathrm{dl}$. Four of the samples registered HB range of $16.4-$ $17.5 \mathrm{~g} / \mathrm{dl}$ and came from $\mathrm{C} 2$ and $\mathrm{C} 4$ where Lopinanavir/Ritonavir and Lopinavir/Ritonavir + diosmin/hesperidin ARVs were administered. HB levels were not registered in 4 of the samples among the 52.There was low risk of hsCRP $(<0.50 \mathrm{mg} / \mathrm{L})$ in all the remaining samples (48).

Samples that registered HBA1C $>6.0 \%$ were four with insulin levels range of between 6.01-6.44 $\mathrm{mU} / \mathrm{L}$ and came from $\mathrm{C} 2$ where Lopinanavir/Ritonavir ARVs were administered. HB levels were normal ranging from $13.7-14 \mathrm{~g} / \mathrm{dl}$ and had low risk of hsCRP $(<0.50 \mathrm{mg} / \mathrm{L})$. The distribution between groups is presented in table 3 .
Table-3: The distribution between groups

\begin{tabular}{|l|l|}
\hline$<\mathbf{4 . 0 \%}$ & 1 \\
\hline $\mathrm{C} 1$ & 6 \\
\hline $\mathrm{C} 5$ & 9 \\
\hline $\mathrm{C} 6$ & \\
\hline $4.0-6.0 \%$ & 11 \\
\hline $\mathrm{C} 1$ & 8 \\
\hline $\mathrm{C} 2$ & 12 \\
\hline $\mathrm{C} 3$ & 12 \\
\hline $\mathrm{C} 4$ & 6 \\
\hline $\mathrm{C} 5$ & 3 \\
\hline $\mathrm{C} 6$ & \\
\hline 6.0 and $>$ & 4 \\
\hline $\mathrm{C} 2$ & \\
\hline
\end{tabular}

Insulin

The insulin levels in the study range from $12.1 \mathrm{mlU} / \mathrm{L}$ to $24.1 \mathrm{mU} / \mathrm{L}$. the expected normal range of insulin is $3.3-22.1 \mathrm{mU} / \mathrm{L}$. Only 13 samples were above $22.1 \mathrm{mU} / \mathrm{L}$ and were in two groups where Lopinanavir/Ritonavir and Atazanavir/ritonavir ARVs were administered. The HBA1C in the 13 samples ranged between $4.87 \%$ and $6.44 \%$. The HB level in the 13 samples ranged from $13.4-17.5 \mathrm{~g} / \mathrm{dl}$. Two samples that registered above normal with $17.5 \mathrm{~g} / \mathrm{dl}$ were from C2 where Lopinanavir/Ritonavir ARVs were administered. The hs-CRP remained $<0.50 \mathrm{mg} / \mathrm{L}$ indicating a low risk of CVD.

The rest 59 samples were within normal range of insulin. HBA1C of the 59 samples ranged between $3.01-5.98 \%$ of which 16 samples registering $<4 \%$. This included C1(1) where no treatment was done, C5 (6) where Atazanavir/Ritonavir +diosmin/hesperidin ARVs were administered and C6 (9) where Diosmin/hesperidin ARVs were administered. HB levels registered range from $7.5-17 \mathrm{~g} / \mathrm{dl}$.

The distribution of those above normal was as shown in table 4;

Table-4: Distribution of Insulin above normal

\begin{tabular}{|l|l|}
\hline Insulin Level above 22.1mU/L & \\
\hline C2 & 9 \\
\hline C3 & 4 \\
\hline
\end{tabular}

\section{Hemoglobin}

There is no result from six (6) samples on HB. They were distributed as follows;

Table-5a: Hemoglobin Distributions

\begin{tabular}{|c|c|}
\hline Group & HB \\
\hline C2 & 2 \\
\hline C3 & 1 \\
\hline C4 & 1 \\
\hline C5 & 1 \\
\hline C6 & 1 \\
\hline
\end{tabular}

Normal range is $11-16 \mathrm{~g} / \mathrm{dl}$ 
Table-5b: Hemoglobin percent Distributions

\begin{tabular}{|l|l|}
\hline Percentage & Number \\
\hline$<11 \mathrm{~g} / \mathrm{dl}$ & 4 \\
\hline $11-16 \mathrm{~g} / \mathrm{dl}$ & 56 \\
\hline$>16 \mathrm{~g} / \mathrm{dl}$ & 6 \\
\hline Total & 66 \\
\hline
\end{tabular}

All the samplers where the HB $<11$ came from C5 and they were four

\section{Table-5c: Hemoglobin Distributions}

\begin{tabular}{|l|l|}
\hline$>11$ g/dl & \\
\hline C5 & 4 \\
\hline $11-16 \mathrm{~g} / \mathrm{dl}$ & \\
\hline $\mathrm{C} 1$ & 12 \\
\hline C2 & 7 \\
\hline C3 & 11 \\
\hline C4 & 10 \\
\hline C5 & 7 \\
\hline C6 & 9 \\
\hline
\end{tabular}

\begin{tabular}{|l|l|}
\hline $16.01 \mathrm{~g} / \mathrm{dl}$ and $>$ & \\
\hline $\mathrm{C} 2$ & 3 \\
\hline $\mathrm{C} 4$ & 1 \\
\hline $\mathrm{C} 6$ & 2 \\
\hline
\end{tabular}

All the samples registered a hs-CRP level of $<0.50 \mathrm{mg} / \mathrm{L}$. this implies a low risk of CVD (heart disease)

\section{Correlations}

The associations between variables were investigated using Pearson product moment correlation coefficient. The results revealed that all variables were positively correlated. There was a moderate positive correlation between HBA1C and Insulin $(r=0.392, p<$ $.001)$. Small relationship existed between $\mathrm{HB}$ and insulin $(r=0.166, p<.001)$, and HBA1C and HB ( $r=$ $0.173, \mathrm{p}<.001)$. Results using all three variables are presented in Table 6.

Table-6: The association between variables

\begin{tabular}{|l|l|c|c|c|}
\hline \multicolumn{5}{|c|}{ Correlations } \\
\hline \multirow{3}{*}{ Pearson Correlation } & HBA1C & HBA1C & Insulin & HB \\
\cline { 2 - 5 } & Insulin & - & - & - \\
\cline { 2 - 5 } & HB & .173 & .166 & - \\
\hline
\end{tabular}

**. Correlation is significant at the 0.01 level (2-tailed).

\section{Normality Assumption Tests}

To assess normality of variables first the original means statistic and 5\% trimmed means statistic of variables in the study were compared. This was to check whether extreme values had a strong influence on the means. It was revealed that there were no much differences between the means as shown in Table 7 , which is an extract from Appendix 1. Therefore extreme values influence on the original means of variables was minimal.

Table-7: Variable Original Means and 5\% Trimmed Mean Comparison
\begin{tabular}{|l|c|c|c|}
\hline & \multicolumn{3}{|c|}{ Statistic } \\
\hline & Original Mean & $\mathbf{5 \%}$ Trimmed Mean & Difference \\
\hline HBA1C & 4.6382 & 4.6382 & 00 \\
\hline Insulin & 20.4747 & 20.6377 & -0.163 \\
\hline HB & 12.6613 & 13.1128 & -0.4515 \\
\hline
\end{tabular}

\section{Research Data (2019)}

After comparing the original means and 5\% trimmed means of the variables, the results of the Kolmogorov-Smirnov statistic was checked. For two variables, value > 0.05 (Appendix 5) were registered, suggesting a violation of assumption of normality. This prompted further investigations by assessing skewness and kurtosis.

Skewness and kurtosis values for the variables were checked and all the variables (HBA1C persuasion -0.193 , Insulin -1.256 and $\mathrm{HB}-2.117$ were negatively skewed. Kurtosis value for HBA1C was negative (0.871) while the other variables registered positive values (Insulin 2.470 and HB 3.861). Since all the kurtosis values were more than 0 , it suggested that the distribution was relatively peaked, hence the risk of underestimation of variance was reduced.

Further investigation involved computing $\mathrm{Z}$ scores for skewness and kurtosis. The computed results revealed that HBA1C $\left(\left|Z_{\text {skewness }}\right|=|-0.682|<1.96\right)$ was normal. However, the $Z$ score values for Insulin $\left(\left|\mathrm{Z}_{\text {skewness }}\right|=|-4.438|>1.96\right)$ and $\mathrm{HB}\left(\left|\mathrm{Z}_{\text {skewness }}\right|=\mid\right.$ $7.481 \mid>1.96)$ violated normality as their $\mid Z$ score $\mid$ of skewness were above 1.96. The $\mathrm{Z}$ score of kurtosis for interpersonal persuasion $\left(\left|Z_{\text {kurtosis }}\right|=|-3.402|>1.96\right)$, subliminal persuasion $\left(\left|Z_{\text {kurtosis }}\right|=|-10.606|>1.96\right)$ and consumer involvement $\left(\left|Z_{\text {kurtosis }}\right|=|-7.510|>1.96\right)$ also moved away from normality. The results of skewness statistic $\left(Z_{\text {skewness }}\right)$ and kurtosis statistic $\left(Z_{\text {kurtosis }}\right)$ values for variables are shown in Table 8 . 
Table-8: Normality Distribution for Variables

\begin{tabular}{|l|c|c|c|c|c|c|}
\hline Variable & \multicolumn{3}{|c|}{ Skewness } & \multicolumn{3}{c|}{ Kurtosis } \\
\cline { 2 - 7 } & Statistic & SE & $\begin{array}{c}\text { Statistic/ } \\
\text { SE }\end{array}$ & Statistic & SE & $\begin{array}{c}\text { Statistic/ } \\
\text { SE }\end{array}$ \\
\hline HBA1C & -0.193 & 0.283 & -0.682 & -0.871 & 0.559 & -1.558 \\
\hline Insulin & -1.256 & 0.283 & -4.438 & 2.470 & 0.559 & 4.419 \\
\hline HB & -2.117 & 0.283 & -7.481 & 3.861 & 0.559 & 6.904 \\
\hline
\end{tabular}

Source: Survey Data (2019)

\section{DisCUSSION}

The research investigated the association between ARVs and development of cardiac diseases. There are six groups in this study labelled C1, C2, C3, $\mathrm{C} 4, \mathrm{C} 5$ and $\mathrm{C} 6 . \mathrm{C} 1$ there is no treatment undertaken i.e. ARVs were not administered, while the other five groups had different ARVs or combinations of ARVs administered. Each group had 12 samples under observation. Table 1 shows the different ARVs administered.

Majority of the samples had HBA1C percentage range between $4.01-6.0 \%$. Normal range of HBA1C was between $4-6 \%$. The insulin level for the samples with <4.0 HBA1C ranged between 12.1 $20.9 \mathrm{mU} / \mathrm{L}$ indication a normal level. HB ranged from $7.5-17.0 \mathrm{~g} / \mathrm{dl}$. Those that were $<11 \mathrm{~g} / \mathrm{dl}$ were three from C5 where Atazanavir/Ritonavir +diosmin/hesperidin ARVs were administered. This could be due to the fact that atazanavir causes reversible hyperbilirubinemia shortly after its administration. The hyperbilirubinemia is common and dose dependent and does not preclude the continuation of therapy with this agent [9]. There was low risk of hsCRP $(<0.50 \mathrm{mg} / \mathrm{L})$ in all the 16 samples. This means that the administration of antiretroviral drugs in wistar rats has low risk of hsCRP. Therefore there is no clear association between ART regimen or treatment duration with hs-CRP levels. This is in agreement with other studies done [10-14]. Systemic inflammation has been implicated in CVD pathogenesis at several stages including atherosclerotic plaque formation, plaque destabilization and rupture, and subsequent myocardial injury [15]. Elevated levels of inflammatory bio markers have been positively associated with CVD risk, fatal CVD events, and overall mortality to varying degrees in the general population [16, 17]. Specifically, elevated hs-CRP concentration appears to predict higher CVD mortality and greater 10-year risk of coronary heart disease (coronary death or MI) in otherwise normal individuals $[18,19]$. Therefore there is need for studies to determine the association between biomarkers and hsCRP. Similarly, the duration of exposure to antiretrovirals is very important and needed to be prolonged.

The 52 samples with $4.0-6.0 \%$ HBA1C had insulin range from $14.2-24.1 \mathrm{~g} / \mathrm{dl}$. Nine of the samples registered insulin range above normal of $22.4-24.1 \mathrm{~g} / \mathrm{dl}$ and came from $\mathrm{C} 2$ and $\mathrm{C} 3$ where Lopinanavir/Ritonavir and Atazanavir/ritonavir ARVs were administered respectively. This is explained by the fact that antiretroviral therapy with HIV protease inhibitor drugs (PI) has been associated with abnormalities in carbohydrate metabolism including insulin resistance, hyperglycemia and development of diabetes mellitus. Atazanavir (ATV) is a PI that affects lipid metabolism significantly less than other PI [20]. Less effect on glucose metabolism is suggested by data from a large clinical trial in treatment-naive patients who initiated an ATV-containing antiretroviral regimen [21]. The lack of significant effect on fasting glucose or insulin levels indicate that ATV may differ on this basis from other available drugs in this class. The fixed-combination PI lopinavir/ritonavir (LPV/r) has also been shown to induce insulin resistance, as assessed by oral glucose tolerance testing in healthy volunteers (5) HB levels ranged between $7.8-17.5 \mathrm{~g} / \mathrm{dl}$. Four of the samples registered $\mathrm{HB}$ range of $16.4-17.5 \mathrm{~g} / \mathrm{dl}$ and came from C2 and C4 where Lopinanavir/Ritonavir and Lopinavir/Ritonavir + diosmin/hesperidin ARVs were administered.

Samples that registered HBA1C $>6.0 \%$ were four with insulin levels range of between $6.01-$ $6.44 \mathrm{mU} / \mathrm{L}$ and came from $\mathrm{C} 2$ where Lopinanavir/Ritonavir ARVs were administered. HB levels were normal ranging from $13.7-14 \mathrm{~g} / \mathrm{dl}$ and had low risk of hsCRP $(<0.50 \mathrm{mg} / \mathrm{L})$. Several studies have suggested a positive association between ART and CVD risk [22-24]. Theoretically hsCRP being a marker of CVD risk should increase with ART. On the contrary, there is also evidence that ART may improve endothelial function and protect against atherosclerosis thereby reducing CVD risk [25-27].This is in agreement with the current study which found no association hence low risk factors in rats administered with Lopinanavir/Ritonavir. Considering these associations, the impact of ARV therapy on hsCRP levels is of significant interest. In ACTG 5056s study, with the introduction of indinavir, hsCRP levels remained stable or decreased slightly over an average of 42 months [28, 29]. A similar slight decline was seen in the HEAT study over 96 weeks following initiation of lopinavir / ritonavir [30]. Both these findings were noted only in men. This is in agreement with this study as only male rats were included. In a study by Shikuma et al. [31] a durably suppressive therapy with efavirenz did not improve hsCRP levels over a 96 week period but was associated with significantly increased levels of CRP in 
women and slight statistically non-significant increase in men. This study also showed that randomization to abacavir had no significant effect on changes in hsCRP levels. Therefore, there is need for a future study that involves both sex i.e. male and females.

The insulin levels in the study range from $12.1 \mathrm{mlU} / \mathrm{L}$ to $24.1 \mathrm{mU} / \mathrm{L}$. the expected normal range of insulin is $3.3-22.1 \mathrm{mU} / \mathrm{L}$. Only 13 samples were above $22.1 \mathrm{mU} / \mathrm{L}$ and were in two groups where Lopinanavir/Ritonavir and Atazanavir/ritonavir ARVs were administered. The HBA1C in the 13 samples ranged between $4.87 \%$ and $6.44 \%$. The HB level in the 13 samples ranged from $13.4-17.5 \mathrm{~g} / \mathrm{d}$ l. Two samples that registered above normal with $17.5 \mathrm{~g} / \mathrm{dl}$ were from C2 where Lopinanavir/Ritonavir ARVs were administered. The rest 59 samples were within normal range of insulin. HBA1C of the 59 samples ranged between $3.01-5.98 \%$ of which 16 samples registering $<4 \%$. This included C1(1) where no treatment was done, C5 (6) where Atazanavir/Ritonavir +diosmin/hesperidin ARVs were administered and C6 (9) where Diosmin/hesperidin ARVs were administered. HB levels registered range from $7.5-$ $17 \mathrm{~g} / \mathrm{dl}$. The addition of diosmin/hesperidin to a regime of atazanavir/ritonavir attenuated its hyperglycaemic effects to the extent did not differ significantly from the control group in terms of the group mean blood glucose levels. This is an important finding that can be considered for the utilization of this combination to counter the hyperglycaemic effects of these drugs in clinical set ups.

The association between variables were investigated using Pearson product moment correlation coefficient. The results revealed that all variables were positively correlated. There was a moderate positive correlation between HBA1C and Insulin $(r=0.392, p<$ $.001)$. This is to the fact that when the body does not convert enough glucose, blood sugar levels remain high. Insulin helps the cells absorb glucose, reducing blood sugar and providing the cells with glucose for energy. When blood sugar levels are too low, the pancreas releases glucagon. HbA1c can be used as a simple and reliable marker of insulin resistance in patients with relatively high insulin sensitivity.

The study reported Small relationship existed between HB and insulin $(\mathrm{r}=0.166, \mathrm{p}<.001)$, and HBA1C and HB $(r=0.173, p<.001)$. The explanation to the observed relationship is that, In addition to physiological parameters, such as temperature, $\mathrm{pH}$, lifetime of protein, substrate concentrations, and individual influencing parameters, the rate of ketoamine formation is dependent on the reactivity of the amino groups. For the hemoglobin molecule, with $2 \mathrm{a}-$ and $2 \mathrm{~b}-$ chains, the terminal amino group of the b-chain is preferred, giving the well-known HbA1c compound. Since erythrocytes are freely permeable to glucose, the rate of formation of $\mathrm{GHb}$ is directly proportional to the ambient glucose concentration in which the erythrocyte circulates to the duration of the exposure and the turnover of the erythrocytes [32].

\section{CONCLUSION}

There is need for studies to determine the association between biomarkers such as hsCRP, IL-6, D-dimer and coronary events. hsCRP needed to be measured in subjects at a specific time, specifics of confounding variables such as details of dyslipidemia type, hypertension stage and duration and glycemic control within the studies to analyze the influence of addition of these markersto the cardiovascular risk scores before implementing routine measurement of hsCRP and to validate its predictability for noncardiovascular morbidity patients on antiretroviral.

\section{FUNDING}

This study did not receive any funding.

\section{REFERENCES}

1. Reingold, J., Wanke, C., Kotler, D. (2008). Association of HIV infection and HIV/HCV coinfection with $\mathrm{C}$-reactive protein levels: the fat redistribution and metabolic change in HIV infection (FRAM) study. J Acquir Immune Defic Syndr, 48:142.

2. Tien, P.C., Choi, A.I., Zolopa, A.R. (2010). Inflammation and mortality in HIV-infected adults: analysis of the FRAM study cohort. $J$ Acquir Immune Defic Syndr, 55:316.

3. Triant, V.A., Meigs, J.B., Grinspoon, S.K. (2009). Association of C-reactive protein and HIV infection with acute myocardial infarction. J Acquir Immune Defic Syndr, 51:268.

4. Aslangul, E., Fellahi, S., Assoumou, L.K. (2011). High-sensitivity C-reactive protein levels fall during statin therapy in $\mathrm{HIV}$-infected patients receiving ritonavir-boosted protease inhibitors. AIDS; 25:1128.

5. Arildsen, H., Sørensen, K.E., Ingerslev, J.M. (2013). Endothelial dysfunction, increased inflammation, and activated coagulation in HIVinfected patients improve after initiation of highly active antiretroviral therapy. HIV Med, 14:1.

6. Hileman, C.O., Wohl, D.A., Tisch, D.J. (2012). Short communication: initiation of an abacavircontaining regimen in $\mathrm{HIV}$-infected adults is associated with a smaller decrease in inflammation and endothelial activation markers compared to non-abacavir-containing regimens. AIDS Res Hum Retroviruses, 28:1561.

7. Martínez, E., D'Albuquerque, P.M., Llibre, J.M. (2012). Changes in cardiovascular biomarkers in HIV-infected patients switching from ritonavirboosted protease inhibitors to raltegravir. AIDS; $26: 2315$. 
8. Hsue, P.Y., Deeks, S.G., Hunt, P.W. (2012). Immunologic basis of cardiovascular disease in HIV-infected adults. $J$ Infect Dis, 205 Suppl 3:S375.

9. Grinspoon, S. (2003). Mechanisms and strategies for insulin resistance in acquired immune deficiency syndrome. Clinical infectious diseases, 37(Supplement_2), S85-S90.

10. Yarasheski, K. E., Tebas, P., Sigmund, C., DagogoJack, S., Bohrer, A., Turk, J., ... \& Powderly, W. G. (1999). Insulin resistance in HIV protease inhibitor-associated diabetes. Journal of acquired immune deficiency syndromes (1999), 21(3), 209.

11. Lee, G. A., Seneviratne, T., Noor, M. A., Lo, J. C., Schwarz, J. M., Aweeka, F. T., ... \& Grunfeld, C. (2004). The metabolic effects of lopinavir/ritonavir in HIV-negative men. AIDS (London, England), 18(4), 641.

12. Wang, S., Mulvey, R., Elosua, C., Flint, O. P., \& Parker, R. A. (2003, August). Association of HIVprotease inhibitors with insulin resistance is related to potency of inhibition of GLUT4 and GLUT1 activity in adipocytes and myocytes. In ANTIVIRAL THERAPY (Vol. 8, No. 4, pp. L36L37). 2-4 IDOL LANE, LONDON EC3R 5DD, ENGLAND: INT MEDICAL PRESS LTD.

13. Haas, D. W., Zala, C., Schrader, S., Piliero, P., Jaeger, H., Nunes, D., ... \& Protocol AI424-009 Study Group. (2003). Therapy with atazanavir plus saquinavir in patients failing highly active antiretroviral therapy: a randomized comparative pilot trial. Aids, 17(9), 1339-1349.

14. Jemsek, J. G., Arathoon, E., Arlotti, M., Perez, C., Sosa, N., Pokrovskiy, V., ... \& Soccodato, M. (2003). Atazanavir and efavirenz, each combined with fixed-dose zidov-udine and lamivudine, have similar effects on body fat distribution in antiretroviral-naive patients: 48-week results from the metabolic substudy of BMS AI424034. Antiviral Therapy, 8(4), L13-L14.

15. Goldsmith, D.R., Perry, C.M. (2003). Atazanavir. Drugs 63:1679-1693.

16. Baker, J. V., Neuhaus, J., Duprez, D., Kuller, L. H., Tracy, R., Belloso, W. H., ... \& Lundgren, J. (2011). Changes in inflammatory and coagulation biomarkers: a randomized comparison of immediate versus deferred antiretroviral therapy in patients with HIV infection. Journal of acquired immune deficiency syndromes (1999), 56(1), 36.

17. Strategies for Management of Antiretroviral Therapy (SMART) Study Group. (2006). CD4+ count-guided interruption of antiretroviral treatment. New England Journal of Medicine, 355(22), 2283-2296.

18. Kuller, L. H., Tracy, R., Belloso, W., De Wit, S., Drummond, F., Lane, H. C., ... \& Paton, N. I. (2008). Inflammatory and coagulation biomarkers and mortality in patients with HIV infection. PLoS med, 5(10), e203.
19. Wada, N. I., Jacobson, L. P., Margolick, J. B., Breen, E. C., Macatangay, B., Penugonda, S., ... \& Bream, J. H. (2015). The effect of HAARTinduced HIV suppression on circulating markers of inflammation and immune activation. AIDS (London, England), 29(4), 463.

20. Guimaraes, M.M., Greco, D.B., Figueiredo, S.M., Foscolo, R.B., Oliveira, A.R., Jr., Machado, L.J. (2008). High-sensitivity C-reactive protein levels in HIV-infected patients treated or not with antiretroviral drugs and their correlation with factors related to cardiovascular risk and HIV infection. Atherosclerosis, 201(2):434-439.

21. Boulware, D. R., Hullsiek, K. H., Puronen, C. E., Rupert, A., Baker, J. V., French, M. A., ... \& Sereti, I. (2011). Higher levels of CRP, D-dimer, IL-6, and hyaluronic acid before initiation of antiretroviral therapy (ART) are associated with increased risk of AIDS or death. Journal of Infectious Diseases, 203(11), 1637-1646.

22. MRFIT Research Group, Kuller, L. H., Tracy, R. P., Shaten, J., \& Meilahn, E. N. (1996). Relation of $\mathrm{C}$-reactive protein and coronary heart disease in the MRFIT nested case-control study. American journal of epidemiology, 144(6), 537-547.

23. Cushman, M., Arnold, A. M., Psaty, B. M., Manolio, T. A., Kuller, L. H., Burke, G. L., ... \& Tracy, R. P. (2005). C-reactive protein and the 10year incidence of coronary heart disease in older men and women: the cardiovascular health study. Circulation, 112(1), 25-31.

24. Currier, J. S., Lundgren, J. D., Carr, A., Klein, D., Sabin, C. A., Sax, P. E., ... \& Working Group 2. (2008). Epidemiological evidence for cardiovascular disease in HIV-infected patients and relationship to highly active antiretroviral therapy. Circulation, 118(2), e29-e35.

25. Currier, J. S., Taylor, A., Boyd, F., Dezii, C. M., Kawabata, H., Burtcel, B., ... \& Hodder, S. (2003). Coronary heart disease in HIV-infected individuals. JAIDS Journal of Acquired Immune Deficiency Syndromes, 33(4), 506-512.

26. Bergersen, B. M. (2006). Cardiovascular risk in patients with HIV infection. Drugs, 66(15), 19711987.

27. Wolf, K., Tsakiris, D. A., Weber, R., Erb, P., Battegay, M., \& Swiss HIV Cohort Study. (2002). Antiretroviral therapy reduces markers of endothelial and coagulation activation in patients infected with human immunodeficiency virus type 1. The Journal of infectious diseases, 185(4), 456462.

28. Torriani, F. J., Komarow, L., Parker, R. A., Cotter, B. R., Currier, J. S., Dubé, M. P., ... \& Squires, K. (2008). Endothelial function in human immunodeficiency virus-infected antiretroviralnaive subjects before and after starting potent antiretroviral therapy: The ACTG (AIDS Clinical Trials Group) Study 5152s. Journal of the American College of Cardiology, 52(7), 569-576. 
29. Henry, K., Kitch, D., Dube, M., Zackin, R., Parker, R. A., Sprecher, D., ... \& Adult AIDS Clinical Trials Group. (2004). C-Reactive protein levels over time and cardiovascular risk in HIV-infected individuals suppressed on an indinavir-based regimen: AIDS Clinical Trials Group 5056s. Aids, 18(18), 2434-2437.

30. McComsey, G. A., Smith, K. Y., Patel, P., Bellos, N. C., Sloan, L., Lackey, P., ... \& Shaefer, M. S. (2009). Similar reductions in markers of inflammation and endothelial activation after initiation of abacavir/lamivudine (ABC/3TC) or tenofovir/emtricitabine (TDF/FTC) in the HEAT study. RNA, 4(1).
31. Shikuma, C. M., Ribaudo, H. J., Zheng, Y., Gulick, R. M., Meyer III, W. A., Tashima, K. T., ... \& Glesby, and the AIDS Clinical Trials Group A5095 Study Team, M. J. (2011). Change in highsensitivity c-reactive protein levels following initiation of efavirenz-based antiretroviral regimens in HIV-infected individuals. AIDS research and human retroviruses, 27(5), 461-468.

32. Shapiro, R., McManus, M. J., Zalut, C., \& Bunn, H. F. (1980). Sites of nonenzymatic glycosylation of human hemoglobin A. Journal of Biological Chemistry, 255(7), 3120-3127.

\section{APPENDICES Appendix 1}

\begin{tabular}{|c|c|c|c|c|}
\hline \multicolumn{5}{|c|}{ Descriptives } \\
\hline & & & Statistic & Std. Error \\
\hline \multirow[t]{13}{*}{ HBA1C } & \multicolumn{2}{|l|}{ Mean } & 4.6382 & .11147 \\
\hline & \multirow[t]{2}{*}{$95 \%$ Confidence Interval for Mean } & Lower Bound & 4.4159 & \\
\hline & & Upper Bound & 4.8605 & \\
\hline & \multicolumn{2}{|l|}{ 5\% Trimmed Mean } & 4.6382 & \\
\hline & \multicolumn{2}{|l|}{ Median } & 4.6650 & \\
\hline & \multicolumn{2}{|l|}{ Variance } & .895 & \\
\hline & \multicolumn{2}{|l|}{ Std. Deviation } & .94588 & \\
\hline & \multicolumn{2}{|l|}{ Minimum } & 3.01 & \\
\hline & \multicolumn{2}{|l|}{ Maximum } & 6.44 & \\
\hline & \multicolumn{2}{|l|}{ Range } & 3.43 & \\
\hline & \multicolumn{2}{|l|}{ Interquartile Range } & 1.34 & \\
\hline & \multicolumn{2}{|l|}{ Skewness } & -.193 & .283 \\
\hline & \multicolumn{2}{|l|}{ Kurtosis } & -.871 & .559 \\
\hline
\end{tabular}

\section{Appendix 2}

\begin{tabular}{|l|c|c|c|c|c|c|}
\hline \multicolumn{7}{|c|}{ Tests of Normality } \\
\hline & \multicolumn{2}{|c|}{ Kolmogorov-Smirnov ${ }^{\mathrm{a}}$} & \multicolumn{3}{c|}{ Shapiro-Wilk } \\
\cline { 2 - 7 } & Statistic & $\mathrm{df}$ & Sig. & Statistic & $\mathrm{df}$ & Sig. \\
\hline HBA1C & \multicolumn{2}{|c|}{72} & $.200^{*}$ & .958 & 72 & .018 \\
\hline *. This is a lower bound of the true significance. \\
\hline
\end{tabular}

\section{Appendix 3}

\begin{tabular}{|c|c|c|c|c|}
\hline \multicolumn{5}{|c|}{ Descriptives } \\
\hline & & & Statistic & Std. Error \\
\hline \multirow[t]{13}{*}{ Insuline } & \multicolumn{2}{|l|}{ Mean } & 20.4747 & .27347 \\
\hline & \multirow[t]{2}{*}{ 95\% Confidence Interval for Mean } & Lower Bound & 19.9294 & \\
\hline & & Upper Bound & 21.0200 & \\
\hline & \multicolumn{2}{|l|}{$5 \%$ Trimmed Mean } & 20.6377 & \\
\hline & \multicolumn{2}{|l|}{ Median } & 20.7900 & \\
\hline & \multicolumn{2}{|l|}{ Variance } & 5.385 & \\
\hline & \multicolumn{2}{|l|}{ Std. Deviation } & 2.32048 & \\
\hline & \multicolumn{2}{|l|}{ Minimum } & 12.10 & \\
\hline & \multicolumn{2}{|l|}{ Maximum } & 24.10 & \\
\hline & \multicolumn{2}{|l|}{ Range } & 12.00 & \\
\hline & \multicolumn{2}{|l|}{ Interquartile Range } & 1.65 & \\
\hline & \multicolumn{2}{|l|}{ Skewness } & -1.256 & .283 \\
\hline & \multicolumn{2}{|l|}{ Kurtosis } & 2.470 & .559 \\
\hline
\end{tabular}




\section{Appendix 4}

\begin{tabular}{|c|c|c|c|c|c|c|}
\hline \multicolumn{7}{|c|}{$\begin{array}{c}\text { Tests of Normality } \\
\end{array}$} \\
\hline & \multicolumn{3}{|c|}{ Kolmogorov-Smirnov $^{\mathrm{a}}$} & \multicolumn{3}{|c|}{ Shapiro-Wilk } \\
\hline & Statistic & df & Sig. & Statistic & $\mathrm{df}$ & Sig. \\
\hline Insulin & .240 & 72 & .000 & .889 & 72 & .000 \\
\hline
\end{tabular}

\section{Appendix 5}

\begin{tabular}{|c|c|c|c|c|}
\hline \multicolumn{5}{|c|}{ Descriptives } \\
\hline & & & Statistic & Std. Error \\
\hline \multirow[t]{13}{*}{$\mathrm{HB}$} & Mean & & 12.6613 & .50931 \\
\hline & \multirow[t]{2}{*}{$95 \%$ Confidence Interval for Mean } & Lower Bound & 11.6457 & \\
\hline & & Upper Bound & 13.6768 & \\
\hline & \multicolumn{2}{|l|}{$5 \%$ Trimmed Mean } & 13.1128 & \\
\hline & \multicolumn{2}{|l|}{ Median } & 13.6500 & \\
\hline & \multicolumn{2}{|l|}{ Variance } & 18.677 & \\
\hline & \multicolumn{2}{|l|}{ Std. Deviation } & 4.32164 & \\
\hline & \multicolumn{2}{|l|}{ Minimum } & .00 & \\
\hline & \multicolumn{2}{|l|}{ Maximum } & 17.50 & \\
\hline & \multicolumn{2}{|l|}{ Range } & 17.50 & \\
\hline & \multicolumn{2}{|l|}{ Interquartile Range } & 2.25 & \\
\hline & \multicolumn{2}{|l|}{ Skewness } & -2.117 & .283 \\
\hline & \multicolumn{2}{|l|}{ Kurtosis } & 3.861 & .559 \\
\hline
\end{tabular}

\section{Appendix 6}

\begin{tabular}{|l|c|c|c|c|c|c|}
\hline \multicolumn{8}{|c|}{ Tests of Normality } \\
\hline \multicolumn{1}{|c|}{ Kolmogorov-Smirnov ${ }^{\mathrm{a}}$} & \multicolumn{3}{|c|}{ Shapiro-Wilk } \\
\cline { 2 - 7 } & Statistic & df & Sig. & Statistic & df & Sig. \\
\hline HB & .282 & 72 & .000 & .696 & 72 & .000 \\
\hline a. Lilliefors Significance Correction \\
\hline
\end{tabular}

